\title{
Association of new-born birth weight with maternal parameters
}

\author{
Anshika Kashyap $^{1 *}$, Pushpinder Kaur ${ }^{2}$, Puneet Srivastava ${ }^{2}$, Veena Singh ${ }^{1}$
}

\begin{abstract}
${ }^{1}$ Department of Obstetrics and Gynecology, ${ }^{2}$ Department of Paediatrics, Al Falah School of Medical Science and Research Centre, Dhouj, Faridabad, Haryana, India
\end{abstract}

Received: 18 July 2019

Revised: 22 July 2019

Accepted: 26 July 2019

\section{*Correspondence:}

Dr. Anshika Kashyap,

E-mail: dranshika76@gmail.com

Copyright: (c) the author(s), publisher and licensee Medip Academy. This is an open-access article distributed under the terms of the Creative Commons Attribution Non-Commercial License, which permits unrestricted non-commercial use, distribution, and reproduction in any medium, provided the original work is properly cited.

\begin{abstract}
Background: Birth weight is the single largest determinant of the neonatal survival and wellbeing. Maternal anaemia is the commonest medical disorder in pregnancy and is associated with significant maternal morbidity and mortality. The effect of haemoglobin levels of the mother on the foetus however remains unclear. This study aims at evaluating the effect of maternal anaemia on neonatal birth weight. It also evaluates the effect of parity, gestational age and maternal age on the new-born birth weight.

Methods: A retrospective study was carried out on patients who had delivered in Al Falah hospital, a newly setup medical college in rural Haryana. The population was studied for maternal age, gestational period, and parity and haemoglobin levels. These parameters were correlated with neonatal birth weight. The study was carried out on deliveries which occurred over a period of six months from November 2018 to April 2019.

Results: The low birth weight new-borns were $10.5 \%$. Maternal anaemia was present in $79.74 \%$ of women in the study group. Amongst all parameters studied, only higher parity and greater period of gestation had a positive correlation with neonatal birth weight. Haemoglobin levels or maternal age didn't show a significant impact on the neonatal birth weight. Anaemic mothers didn't have a higher incidence of low birth weight babies.

Conclusion: The most significant contributor to improved neonatal weight is the gestational age of the foetus. All efforts to ensure better neonatal outcome must primarily concentrate on prevention of preterm births. Maternal haemoglobin levels do not directly impact the neonatal birth weight. However, as anaemia is a risk factor for preterm delivery, anaemia indirectly impacts on the neonatal birth weight and outcome.
\end{abstract}

Keywords: Anaemia, Neonatal birth weight, Maternal characteristics

\section{INTRODUCTION}

Birth weight of an infant is the single largest determinant of its chance of survival, health, growth and development.

Low birth weight infants are more vulnerable and exposed to different health problems and complications compared with normal birth weight babies. Birth weight is the major determinant of mortality, morbidity and disability in infancy and childhood. It also has a long term impact on health outcome in adult life. Low birth weight is defined as a birth weight below $2500 \mathrm{gms}$. The prevalence of low birth weight babies in developing countries $(16.5 \%)$ is twice that in developed countries $(7 \%) .^{1,2}$

It is generally assumed that prevention of LBW results in a corresponding reduction in perinatal mortality. ${ }^{3}$ The 
identification of factors contributing to low birth weight is therefore important.

Anaemia is the commonest medical complication in pregnancy. 14-62\% patients in developing countries and $16-29 \%$ in developed countries are suffering from anaemia. ${ }^{4}$ Maternal anaemia influences perinatal outcomes such as risk of low birth weight, mode of delivery. ${ }^{5}$

There have been various studies showing varying associations between maternal anaemia and adverse pregnancy outcomes. Hamalainen et al, showed that anaemia in early pregnancy is associated with low birth weight. ${ }^{6}$ In contrast, studies by Abaysena et al, did not find any association between maternal anaemia and adverse pregnancy outcomes. ${ }^{7}$ Further, Malhotra et al, in their study observed that mean birth weight was highest in babies with mild anaemia in mother. ${ }^{8}$

The objective of this study was to evaluate the association between maternal anaemia and low birth weight infant in women delivering in Al Falah hospital, a new medical college in rural Haryana. This hospital has a very high prevalence of maternal anaemia.

New-born birth weight was also correlated with other factors like maternal age, gestational age at the time of delivery and parity.

\section{METHODS}

The present study is a retrospective study conducted in $\mathrm{Al}$ Falah hospital, a new Medical College in rural Haryana. Delivery records and case sheets of patients who delivered between $1^{\text {st }}$ November 2018 and $30^{\text {th }}$ April 2019 were extracted from medical records department and studied. The population belonged to low socioeconomic strata with low levels of education.

Inclusion criteria were singleton pregnancies between 34 42 weeks. The gestational age criterion of 34-42 weeks that is selected is because our hospital accepts all mothers at more than 34 weeks gestational age at the time of labour. Admissions before 34 weeks are decided on case to case basis only after consultation with paediatric department and a large number of estimated low birth weight babies maybe referred which might confound results. Babies born before 34 weeks gestational age were thus excluded. Babies born to mothers with known antepartum complications like preeclampsia, antepartum haemorrhage and medical complications like diabetes, hypertension were excluded. Babies found to have congenital anomalies and stillbirths were also excluded. Mothers with BMI less than 19 and over 30 at the time of delivery and patients with incomplete records with respect to gestational age were further excluded. The parity as also maternal age was noted. The gestational age at the time of delivery was calculated based on the last menstrual period or a first trimester scan. A note was made of the birth weight of the infants.

There were 390 patients fulfilled the inclusion and exclusion criteria. Haemoglobin levels are routinely checked at the time of delivery in our institute. These were noted and patients were categorized as those with normal haemoglobin levels and those with mild anaemia $(10-10.9 \mathrm{~g} / \mathrm{dl})$, moderate $(7-9.9 \mathrm{~g} / \mathrm{dl})$ and severe anaemia $(<7 \mathrm{~g} / \mathrm{dl})$ according to WHO criteria. Frequencies and percentages were calculated in respect of above variables and mean birth weight, gestational age, maternal age was calculated. The impact of the above factors on the birth weight was calculated by linear regression analysis and chi square test.

\section{RESULTS}

There were 390 patients who delivered over a period of six months from 1st November 2018 till 30th April 2019 were included in the study. 41 of these mothers $(10.5 \%)$ delivered babies with low birth weight. 349 infants (89.5\%) had birth weight above 2500 gms.

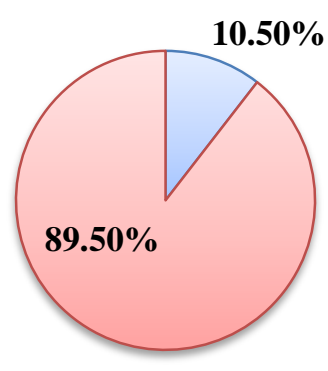

$\square$ low birth weight $\square$ normal birth weight

Figure 1: Percentage of low birth weight babies.

Table 1: Distribution of various variables amongst the cases.

\begin{tabular}{|lllllllll|}
\hline Variables & No. & Mean & SD & Median & IQR & Mode & Minimum & Maximum \\
\hline Maternal Age (years) & 390 & 25.33 & 4.63 & 25.00 & 6.00 & 22.00 & 18.00 & 45.00 \\
\hline Birth Weight (Kg) & 390 & 2.97 & 0.46 & 3.00 & 0.70 & 3.00 & 1.40 & 4.20 \\
\hline Period of Gestation (weeks) & 390 & 36.56 & 2.06 & 37.00 & 4.00 & 34.00 & 34.00 & 42.00 \\
\hline $\mathrm{Hb}(\mathrm{gm} \%)$ & 390 & 9.18 & 1.87 & 9.40 & 2.80 & 8.20 & 4.80 & 13.50 \\
\hline
\end{tabular}


Table 1 shows the distribution of the cases with respect to maternal age, birth weight, period of gestation and haemoglobin in gm\%.

The mean age of the study group was 25.33 years with the youngest patient 18 years of age and the oldest 45 years old. The mean birth weight was $2.97 \mathrm{~kg}$ with the maximum being $4.2 \mathrm{~kg}$ and minimum being $1.4 \mathrm{~kg}$ in weight. The median gestational age at birth was 37 weeks. The mean haemoglobin was $9.18 \mathrm{gm} \%$ with the lowest haemoglobin in study population being $4.8 \mathrm{gm} \%$ and the highest $13.5 \mathrm{gm} \%$.

Table 2 shows that the largest group of patients belonged to the 23-27 years age group (158) followed by 18-22 years age group (125). 283 mothers in the study population were below 27 years of age. The primigravidas were 100 whereas the remaining 290 were multigravidas.

Table 2: Distribution of various variables amongst the cases.

\begin{tabular}{|lll|}
\hline Maternal Age (years) & No. & Percentage \\
\hline 18 to 22 & 125 & $32.1 \%$ \\
\hline 23 to 27 & 158 & $40.5 \%$ \\
\hline 28 to 32 & 82 & $21.0 \%$ \\
\hline 33 to 37 & 16 & $4.1 \%$ \\
\hline 38 to 42 & 7 & $1.8 \%$ \\
\hline 42 and above & 2 & $0.5 \%$ \\
\hline
\end{tabular}

There were $164(42.1 \%)$ of the patients were between 3437 weeks of gestation whereas 226 (57.9\%) of the patients delivered at term i.e. beyond 37 weeks of gestation. A large number i.e. 117 patients delivered at 34 weeks of gestation.

There were $311(79.4 \%)$ of the mothers were anaemic. $281(90.35 \%)$ of these anaemic mothers delivered babies with normal birth weight. Only $9.65 \%$ i.e. 30 of the mothers who were detected to be anaemic delivered low birth weight babies. The degree of anaemia also didn't have an impact on the birth weight. $13.92 \%$ i.e. 11 of the 79 patients who had normal haemoglobin levels delivered babies with low birth weight.

Table 3: Distribution on basis of period of gestation in weeks.

\begin{tabular}{|lll|}
\hline Period of Gestation (weeks) & No. & Percentage \\
\hline 34 & 117 & $30.0 \%$ \\
\hline 35 & 14 & $3.6 \%$ \\
\hline 36 & 33 & $8.5 \%$ \\
\hline 37 & 93 & $23.8 \%$ \\
\hline 38 & 68 & $17.4 \%$ \\
\hline 39 & 38 & $9.7 \%$ \\
\hline 40 & 14 & $3.6 \%$ \\
\hline 41 & 10 & $2.6 \%$ \\
\hline 42 & 3 & $0.8 \%$ \\
\hline Total & 390 & $100.0 \%$ \\
\hline
\end{tabular}

Thus, low birth weight babies were born to mothers with adequate haemoglobin levels with the same frequency as those born to anaemic mothers. The correlation of haemoglobin with birth weight was thus found to be not significant. Low haemoglobin levels were not a risk factor for low birth weight.

The patients had uniform distribution of birth weights with respect to maternal haemoglobin levels. High or low haemoglobin levels didn't result in corresponding increase or decrease in birth weight.

Linear Regression showed Haemoglobin was not a statistically significant predictor of New-born Birth weight $(\mathrm{p}$-value $=0.448)$.

Table 4: Association among the cases between haemoglobin (gm.\%) and birth weight status.

\begin{tabular}{|c|c|c|c|c|}
\hline \multirow{2}{*}{ Haemoglobin status } & \multicolumn{3}{|c|}{ Birth weight } & \multirow[t]{2}{*}{ Total } \\
\hline & \multicolumn{2}{|c|}{ Low birth weight } & Normal Birth Weight & \\
\hline \multirow[t]{2}{*}{ Severe Anaemia } & No. & 7 & 48 & 55 \\
\hline & $\%$ & $12.7 \%$ & $87.3 \%$ & $100.0 \%$ \\
\hline \multirow[t]{2}{*}{ Moderate Anaemia } & No. & 14 & 160 & 174 \\
\hline & $\%$ & $8.0 \%$ & $92.0 \%$ & $100.0 \%$ \\
\hline \multirow[t]{2}{*}{ Mild Anaemia } & No. & 9 & 73 & 82 \\
\hline & $\%$ & $11.0 \%$ & $89.0 \%$ & $100.0 \%$ \\
\hline \multirow[t]{2}{*}{ Normal Haemoglobin } & No. & 11 & 68 & 79 \\
\hline & $\%$ & $13.9 \%$ & $86.1 \%$ & $100.0 \%$ \\
\hline \multirow[t]{2}{*}{ Total } & No. & 41 & 349 & 390 \\
\hline & $\%$ & $10.5 \%$ & $89.5 \%$ & $100.0 \%$ \\
\hline Chi-Square Test & Value & Df & p-value & Association is- \\
\hline Pearson Chi-Square & 2.408 & 3 & 0.492 & Not significant \\
\hline
\end{tabular}


Table 5: Linear Regression between Birth weight (kg) as dependent variable and haemoglobin as independent variable.

\begin{tabular}{|c|c|c|c|c|c|}
\hline $\mathbf{R}$ & R Square & $\begin{array}{l}\text { Adjusted R } \\
\text { Square }\end{array}$ & \multicolumn{3}{|l|}{ Std. error of the estimate } \\
\hline 0.038 & 0.001 & -0.001 & \multicolumn{3}{|l|}{0.4595} \\
\hline \multicolumn{6}{|l|}{ ANOVA (Model 1) } \\
\hline & Sum of Squares & Df & Mean Square & F-value & p-value \\
\hline Regression & 0.122 & 1 & 0.122 & 0.576 & 0.448 \\
\hline Residual & 81.934 & 388 & 0.211 & \multirow{2}{*}{\multicolumn{2}{|c|}{$\begin{array}{l}\text { Difference is not } \\
\text { significant }\end{array}$}} \\
\hline Total & 82.055 & 389 & & & \\
\hline \multicolumn{6}{|l|}{ Coefficients (Model 1) } \\
\hline \multirow{2}{*}{ Items } & \multicolumn{2}{|c|}{ Unstandardized coefficients } & Standardized coefficients & \multirow{2}{*}{ t-value } & \multirow{2}{*}{ p-value } \\
\hline & $\mathrm{B}$ & Std. Error & Beta & & \\
\hline (Constant) & 3.06 & 0.117 & & 26.191 & $44 \mathrm{E}-88$ \\
\hline Haemoglobin (gm \%) & -0.009 & 0.012 & -0.038 & -0.759 & 0.448 \\
\hline
\end{tabular}

Table 6: Linear regression between birth weight (kg) as dependent variable and period of gestation, maternal age, haemoglobin and gravida status as independent (predictor) variable.

\begin{tabular}{|c|c|c|c|c|c|}
\hline \multicolumn{6}{|l|}{ Model Summary (Model 1) } \\
\hline $\mathrm{R}$ & R Square & Adjusted R Square & \multicolumn{3}{|l|}{$\begin{array}{l}\text { Std. Error of the } \\
\text { Estimate }\end{array}$} \\
\hline 0.504 & 0.254 & 0.244 & 0.3994 & & \\
\hline \multicolumn{6}{|l|}{ ANOVA (Model 1) } \\
\hline & $\begin{array}{l}\text { Sum of } \\
\text { Squares }\end{array}$ & Df & Mean Square & F-value & p-value \\
\hline Regression & 20.812 & 5 & 4.162 & 26.098 & $1.07 \mathrm{E}-22$ \\
\hline Residual & 61.244 & 384 & 0.159 & \multirow{2}{*}{\multicolumn{2}{|c|}{ Difference is not significant }} \\
\hline Total & 82.055 & 389 & & & \\
\hline \multicolumn{6}{|l|}{ Coefficients (Model 1) } \\
\hline \multirow[t]{2}{*}{ Items } & \multicolumn{2}{|c|}{ Unstandardized Coefficients } & $\begin{array}{l}\text { Standardized } \\
\text { Coefficients }\end{array}$ & \multirow[t]{2}{*}{ t-value } & \multirow[t]{2}{*}{$\mathrm{p}$-value } \\
\hline & $\mathrm{B}$ & Std. Error & Beta & & \\
\hline (Constant) & -1.206 & 0.401 & & -3.006 & 0.003 \\
\hline Haemoglobin $(\mathrm{gm} \%)$ & -0.011 & 0.011 & -0.043 & -0.965 & 0.335 \\
\hline Maternal Age (years) & -0.002 & 0.005 & -0.018 & -0.363 & 0.717 \\
\hline $\begin{array}{l}\text { Gravida status } \\
\text { (Primigravida }=1 \text {, Multipara=2) }\end{array}$ & 0.120 & 0.052 & 0.114 & 2.312 & 0.021 \\
\hline Period of Gestation (weeks) & 0.108 & 0.010 & 0.485 & 10.927 & $2.19 \mathrm{E}-24$ \\
\hline
\end{tabular}

It was found that the birth weight increased with increase in gestational age. Multigravidas delivered babies of higher mean birth weight than primigravidas.

Linear regression analysis of all the variables analysed showed that only gravidity and period of gestation were statistically significant predictors of birth weight. Maternal age and haemoglobin levels didn't significantly affect neonatal birth weight.

\section{DISCUSSION}

The present study showed a $10.5 \%$ prevalence of low birth babies. A study in Pakistan showed a $10.6 \%$ prevalence of low birth weight babies in term infants. ${ }^{9}$
This is very low compared to a similar study by Noor $\mathrm{N}$ et al, which reported a $36.8 \%$ prevalence. ${ }^{10}$ Our centre is a newly established facility. The lower prevalence in our study maybe because a large number of high risk patients opt to go to the government referral centre nearby.

Our study concluded that haemoglobin levels have no significant effect on the new-born birth weight. This was in contrast to independent studies by Nair $\mathrm{N}$ et al, and Levy et al, which showed that anaemic mothers delivered lower birth weight babies. ${ }^{11,12}$

In contrast, Steer and colleagues showed that low haemoglobin concentration $(85-105 \mathrm{~g} / \mathrm{L})$ is associated with maximum mean birth weight and lowest incidence 
of low birth weight. ${ }^{13}$ Malhotra et al, observed that mean birth weight was highest in babies whose mothers had mild anaemia with haemoglobin concentration between 9.6 and $10.5 \mathrm{gm} \%{ }^{8}$

The findings in current study indicate that gestational age and parity are significant determinants of neonatal birth weight. It was found that the birth weight improves with gestational age. This is in concurrence with studies by Negi et al, and Deshmukh et al, which reported that the risk of low birth weight was higher in lower gestational ages. $^{14,15}$

In our study, multiparous patients had overall higher mean birth weight babies than primiparous patients. A large volume of data shows that birth weight increases with birth order. This is supported by studies by Celik et al, which concluded that birth order is a major factor affecting birth weight. ${ }^{16}$ Hirve and Ganatra also found a 1.3 times higher relative risk for low birth weight in primiparas. $^{17}$

Maternal age was not found to have a significant correlation with birth weight. However, there was no mother below 18 years in our study group. A study in South India highlighted that both young teenagers and older women are at risk for delivering low birth weight babies. $^{18}$

Thus, Authors conclude that gestational age and parity are significant contributors to the new-born birth weight. Similar findings were reported by a study by Noor $\mathrm{N}$ et al, who concluded that gestational age and parity are major risk factors influencing the birth weight of the baby. ${ }^{10}$

The study population shows a large number of patients $(42.1 \%)$ delivered before 37 weeks. This could be due to factors like poor nutritional status, multiparity, infections and poor birth spacing.

Anaemia was detected in $79.4 \%$ of the mothers. Various studies have pointed out that patients with low haemoglobin levels are more prone to preterm delivery and infections. This is a retrospective study and a large number of patients have inadequate antenatal follow up. A further prospective study to correlate maternal haemoglobin levels in various trimesters with preterm delivery will have to be carried out after correcting for confounding variables like presence of urinary tract, dental infections as well as maternal smoking. This would further establish if anaemia has an indirect role to play in the birth weight due to preterm delivery. ${ }^{19}$

\section{CONCLUSION}

Our study concluded that anaemia didn't significantly have an impact on the birth weight of the new-born. Further, it concluded that the gestational age is the single largest determinant of the birth weight .All efforts to improve neonatal birth weight must therefore be targeted primarily at prevention of preterm birth.

Funding: No funding sources

Conflict of interest: None declared

Ethical approval: The study was approved by the Institutional Ethics Committee

\section{REFERENCES}

1. Borja JB, Adair LS. Assessing the net effect of young maternal age on birth weight. Am J Hum Biol. 2003 Nov;15(6):733-40.

2. P.Bharati, M Pal, M Bandopadhyay, A Bhakta, S Chakraborty, P. Bharati. Prevalence and causes of low birth weight in India. Malays J Nutr. 2011 Dec;17(3):301-13.

3. Wasunna A, Mohammed K. Low birth weight babies: Socio-demographic and obstetric characteristics of adolescent mothers at Kenyatta National Hospital, Nairobi. East Afr Med J.2002; 79(10):543-6.

4. Shobeiri F, Begum K, Nazar M. A prospective study of maternal haemoglobin status of Indian women during pregnancy and pregnancy outcome. Nutr. Res. 2006 May 1;26(5):209-13.

5. Amalia LA, Diora FB, Miriam Katz C, Moshe Mc, Eyal S. Maternal anaemia during pregnancy is an independent risk factor for low birth weight and preterm delivery; EJOGRB. Elsevier Ireland Ltd. 2005 Oct 1;122(2):182-6.

6. Hamalainen H, Hakkkainenn K, Heinone S. Anaemia in the first but not in the second or third trimester is a risk factor for low birth weight. Clin Nutr. 2003;22(30):271-5.

7. Abeysena C, Jayawardana P, de Seneviratne AR. Maternal haemoglobin at booking visit and its effect on adverse pregnancy outcome. Aust NZJ Obstet Gynecol. 2010;509(5):423-7.

8. Malhotra M, Sharma JB, Batra S, Sharma S, Murthy NS, Arora R. Maternal and perinatal outcome in varying degrees of anaemia. Int $\mathrm{J}$ Gynecol Obstet. 2002:79(2):93-100.

9. A. Khun, F.D. Nasrullah, R. Jaleel. Frequency and risk factors of low birth weight in term pregnancy. PJMS, 2016 Jan;32(1):138-42.

10. Noor N, Kural M, Joshi T, Pandit D, Patil A. Study of maternal determinants influencing birth weight of new-born. Arch Med Health Sci. 2015 Jul 1;3(2):239-43.

11. Nair M, Gireesh S, Yakoob R, Cherain NC. Effect of maternal anaemia on birth weight of term babies. Int J. Contemp Pediatr. 2018 May;5(3):1019-22.

12. Levy A, Fraser D, Katz M, Mazor M, Sheiner E. Maternal anaemia during pregnancy is an independent risk factor for low birth weight and preterm delivery. Eur J Obstet Gynecol Reprod Biol. 2005,122(2);182-6. 
13. Whitaker PG, Macphil S, Lind T. Serial haematological changes and pregnancy outcome. Obs and Gynae, 1996:88(1):33-9.

14. Negi KS, Kandpal SD, Kukreti M. Epidemiological factors affecting low birth weight. JK Sci J Med Edu Res. 2006 Jan 23;8(1):31-4.

15. Deshmukh JS, Motghare DD, Zodpey SD, Wadhva SK: Low birth weight and associated maternal factors in an urban area Indian Paediatr. 1998:35(1):33-6.

16. Celik Y, Younez HZ, Effects of antenatal care services on birth weight, importance of model specification and empirical procedure used in estimating the marginal productivity of health inputs. J Med Syst. 2007 Jun 1;31(3):197-204.

17. Hirve SS, Ganatra BR. Determinants of low birth weight. A community based cohort study Indian Pediatr. 1994 Oct 1;31(10):1221-5.
18. Aras RY. Is maternal age a risk factor for low birth weight? Arch Med Health Sci. 2013 Jan 1;1(1):33-7.

19. Kant S, Kaur R, Goel AD, Malhotra S, Haldar P, Kumar R. Anaemia at the time of delivery and its association with pregnancy outcome: A study from a secondary care hospital in Haryana, India. India $\mathbf{J}$ Public Health 2018 Oct 1;62(4):315-8.

Cite this article as: Kashyap A, Kaur P, Srivastava P, Singh V. Association of new-born birth weight with maternal parameters. Int J Reprod Contracept Obstet Gynecol 2019;8:3453-8. 